ISSN 2525-4804

\title{
QUALIDADE NUTRICIONAL E CULINÁRIA DE CULTIVARES DE ARROZ ADUBADO COM DOSES DE NITROGÊNIO
}

\author{
Isabela Pires de Castro Faria ${ }^{1}$; Jeane Castro Fonseca ${ }^{2}$; Caroline Roberta Freitas Pires ${ }^{3}$; Expedito \\ Alves Cardoso ${ }^{4}$; Nayara Monteiro Rodrigues ${ }^{5}$; Diego Neves de Sousa ${ }^{6}$
}

\section{RESUMO:}

O mercado consumidor no cenário atual está se voltando para uma busca de melhor produtividade e qualidade dos grãos de arroz. Diante disso, o objetivo deste trabalho foi avaliar a qualidade nutricional e culinária de cultivares de arroz adubados com diferentes doses de nitrogênio. As amostras foram avaliadas quanto ao teor de umidade, lipídios, proteínas, fibras, cinzas, carboidratos, valor calórico, coloração, tempo mínimo de cocção, absorção de água e percentual de rendimento de grãos inteiros. As doses de nitrogênio avaliadas não influenciaram nos teores de proteínas e no rendimento de grãos inteiros. A cultivar BRS Primavera apresentou maior percentual de rendimento de grãos inteiros, enquanto a cultivar BRS Sertaneja apresentou maiores teores de proteína e grãos de coloração mais escura.

Palavras chave: Oryza sativa, adubação nitrogenada, nutrição.

\section{NUTRITIONAL AND COOKING QUALITY OF RICE CULTIVARS FERTILIZED WITH NITROGEN DOSES}

\begin{abstract}
:
In the current scenario, the consumer market is turning to a search for better productivity and quality of rice grains. Therefore, the objective of this work was to evaluate the nutritional and culinary quality of rice cultivars different fertilized with nitrogen doses. The samples were evaluated for: moisture content, lipids, proteins, fibers, ashes, carbohydrates, caloric value, color, minimum cooking time, water absorption, and percentage of whole grain yield. The nitrogen doses evaluated did not influence protein content and wholegrain yield. The cultivar BRS Primavera showed a higher percentage of whole grain yield, while the cultivar BRS Sertaneja showed higher levels of protein and grains of darker color.
\end{abstract}

KeyWords: Oryza sativa, nitrogen fertilization, nutrition.

\footnotetext{
${ }^{1}$ Nutricionista (UFT), isabelapiresnutri@gmail.com

${ }^{2}$ Nutricionista (UFT), jeanecfnutri@ outlook.com

${ }^{3}$ Doutora em Ciências dos Alimentos (UFLA), Professora do Curso de Nutrição (UFT), carolinerfpires@mail.uft.edu.br

${ }^{4}$ Doutor em Fitotecnia (UFV), Professor/pesquisador (UNITINS), expedito.ac@gmail.com

${ }^{5}$ Mestra em Agroenergia (UFT), nayara.nmr@hotmail.com

${ }^{6}$ Doutor em Desenvolvimento Rural (UFRGS), analista da Embrapa Pesca e Aquicultura, diego.sousa@embrapa.br
} 


\section{INTRODUÇÃO}

O arroz (Oryza sativa L.) é considerado um dos alimentos mais antigos da humanidade e constitui até hoje uma das principais fontes de energia, além de contribuir significativamente para a segurança alimentar e nutricional de boa parte da população mundial. É considerado um dos cereais básicos da dieta humana e está entre os três cereais internacionalmente mais produzidos e consumidos, ficando atrás somente do trigo (Triticum sp. L.) e do milho (Zea mays L.). No Brasil, o arroz é o cereal mais consumido (Kennedy \& Burlingame, 2003; Oliveira et al., 2014).

De acordo com a Conab (2019), na Safra 2017/18, o país produziu 11,2 milhões de toneladas de arroz. Numa projeção da safra brasileira de 2018/2019, a produção foi 12,2\% (10,6 t) inferior à safra anterior. Trata-se, assim, de um volume abaixo da média histórica de 12 milhões de toneladas. Esses dados retratam uma perspectiva menor de produtividade justificada pelas adversidades climáticas e pela redução de área nos principais estados brasileiros produtores de arroz.

Do ponto de vista nutricional, o consumo de arroz como alimento básico de dietas saudáveis é indicado em todas as normas e guias alimentares para a população brasileira (Brasil, 2014). Além do seu alto valor energético, devido à alta concentração de amido, fornece também proteínas, vitaminas como as do complexo $\mathrm{B}$, minerais como o fósforo, cálcio e ferro e, ainda, possui baixo teor de lipídios (Kennedy \& Burlingame, 2003).

O carboidrato desse cereal é constituído de duas macromoléculas de amido: a amilose e a amilopectina. Assim, o teor de amilose está vinculado com propriedades como a maciez, brilho, coesão, volume de absorção de água, cor e expansão, no qual pode relacionar com as mudanças que ocorrem durante o processo de cocção e que determinam a qualidade culinária do arroz (Kennedy \& Burlingame, 2003).

As características do arroz refletem diretamente na comercialização do produto, sendo que um produto homogêneo sem presença de grãos danificados ou quebrados são os de maior saída no mercado. Com isso, o objetivo dos produtores e cerealistas é um adequado beneficiamento com a capacidade de produzir maior quantidade de grãos inteiros (Cuevas \& Peske, 1990).

Uma das técnicas utilizadas com a finalidade de obter aumento na produtividade da cultura e redução do custo de produção é a adubação nitrogenada. O nitrogênio é um componente estrutural importante da planta, faz parte das proteínas, aminoácidos, ácidos nucléicos, membranas e enzimas considerado o segundo mineral que a planta mais acumula (Buzetti et al., 2006). Apesar das diversas cultivares de arroz se comportarem de modo diferente a aplicação do nitrogênio, este, de modo geral, quando utilizado em teor adequado, pode refletir no tamanho e na quantidade dos grãos (Fageria et al., 2007).

O cenário atual do mercado consumidor está se voltando para uma melhor produtividade $\mathrm{e}$ qualidade do grão, visto que consumidores procuram cada vez mais produtos com melhor qualidade. Diante disso, o objetivo deste trabalho foi avaliar as qualidades nutricionais e culinárias de duas cultivares de arroz, submetidas a doses de nitrogênio.

\section{MATERIAIS E MÉTODOS}

O experimento foi conduzido no Complexo de Ciências Agrárias (CCA) da Universidade Estadual do Tocantins (UNITINS), Palmas-TO, coordenadas $10^{\circ} 29^{\prime} 02$ 'S, $8^{\circ} 20^{\prime} 05^{\prime \prime} \mathrm{O}$ e altitude $247 \mathrm{~m}$, durante o período de janeiro a maio de 2015. As sementes do presente estudo tiveram origem de um ensaio pertencente à Embrapa Arroz e Feijão. O solo onde o experimento foi conduzido é classificado como Latossolo Vermelho Amarelo com textura média que apresentou as seguintes características: $\mathrm{pH}$ em água 5,09; Fósforo disponível 1,7 $\mathrm{mg} \mathrm{dm}^{-3}$; Potássio disponível 37,377 $\mathrm{mg} \mathrm{dm}^{-3}$; Cálcio + Magnésio 2,9 cmolc $\mathrm{dm}^{-3}$; Alumínio 0,27 cmolc $\mathrm{dm}^{-3}$; Acidez potencial 14,4 $\mathrm{cmolc} \mathrm{dm}^{-3}$; Soma de Bases $3 \mathrm{cmolc}$ 
$\mathrm{dm}^{-3}$; C.T.C. 4,2 cmolc dm $\mathrm{dm}^{-3}$; pH 7,0; Saturação por Bases 17,22\%; Saturação por Alumínio 8,27\%; teor de matéria orgânica $18 \mathrm{~g} \mathrm{~kg}^{-1}$; valores de textura 608 $\mathrm{g} \mathrm{kg}^{-1}$ de areia, $70,4 \mathrm{~g} \mathrm{~kg}^{-1}$ de silte e $321,6 \mathrm{~g} \mathrm{~kg}^{-1}$ de argila. O preparo do solo foi o convencional com uma aração e duas gradagens.

Foram avaliadas as cultivares BRS Primavera e BRS Sertaneja. A BRS Primavera possui tipo moderno, com folhas eretas e alto perfilhamento. Possui altura de planta média de $110 \mathrm{~cm}$ e ciclo médio de 90 dias. É medianamente susceptível ao acamamento. Com relação às doenças, é moderadamente susceptível à brusone na panícula e à brusone na folha; moderadamente resistente à mancha parda, à escaldadura das folhas e à mancha dos grãos (Lanna, Ferreira, Barrigossi, 2003).

Já a BRS Sertaneja é uma cultivar caracterizada por plantas vigorosas, moderadamente perfilhadoras, porte médio e folhas largas. Suas panículas são longas e com elevado número de espiguetas. Possui altura de planta média de $107 \mathrm{~cm} \mathrm{e}$ ciclo médio de 110 dias, além de possuir mediana resistência ao acamamento. É uma cultivar de ampla adaptação e com maior resistência a brusone, sendo uma cultivar precoce de terras altas (Breseghello et al., 2007).

As referidas cultivares foram submetidas à aplicação de três doses de nitrogênio, sendo estas de 0; 80 e $240 \mathrm{~kg} \mathrm{ha}^{-1}$ de $\mathrm{N}$. A adubação nitrogenada foi parcelada em duas aplicações, uma aos 30 dias e outra aos 60 dias após o plantio, sendo a ureia a fonte de nitrogênio utilizada. $O$ ciclo da cultura foi estabelecido de 110 a 120 dias, no qual a colheita dos grãos foi realizada quando eles apresentaram teor de umidade entre 18 e $20 \%$.

$\mathrm{O}$ experimento foi instalado em delineamento de Blocos ao Acaso (DBC) em três parcelas de $5 \mathrm{x}$ 1,5m de largura e distância entre linhas de $0,3 \mathrm{~m}$. A área do experimento foi de $35 \times 15 \mathrm{~m}$, totalizando 525 $\mathrm{m}^{2}$. O plantio foi realizado no dia 21 de janeiro de 2015.

Após a colheita dos grãos no campo foi retirado cerca de 100 gramas de arroz de cada repetição. Estas foram conduzidas ao beneficiamento em testadora de arroz da marca Suzuki MT 10 (Máquinas Suzuki, SP, Brasil), obtendo-se o arroz descascado e com o mesmo grau de polimento. O rendimento de grãos foi expresso pelo percentual de grãos inteiros.

Em seguida, as amostras dos grãos beneficiados foram conduzidas para o Laboratório de Tecnologia de Alimentos da Universidade Federal do Tocantins, para serem, então, processadas, visando obter uma amostra representativa de todo o experimento conduzido.

Para a análise da composição centesimal das amostras de arroz das cultivares BRS Primavera e BRS Sertaneja submetidas a aplicação de doses de nitrogênio, foram adotadas as normas do Official Methods of the Association of the Agricultural Chemists (AOAC, 2000), pelos quais foram determinados os teores de umidade, lipídios, proteínas, carboidratos e cinzas.

O teor de umidade foi determinado pelo método gravimétrico com emprego de calor, conforme as normas da AOAC (2000), cujas amostras foram conduzidas à estufa até sua completa desidratação. O extrato etéreo foi obtido por extração com solvente orgânico (hexano) por meio do auxílio de aparelho extrator do tipo Soxhlet (AOAC, 2000).

A proteína bruta foi analisada por meio do teor de nitrogênio mediante destilação em aparelho de Kjedahl, utilizando-se o fator de conversão de 5,83 para o cálculo do teor de proteína bruta (AOAC, 2000).

A fração de cinzas foi determinada por meio do método gravimétrico, avaliando-se a perda de peso do material submetido ao aquecimento em mufla a 550-660 ${ }^{\circ} \mathrm{C}$ (AOAC, 2000).

Para a determinação de fibras, foi utilizado o método gravimétrico proposto por Kamer \& Ginkel (1952), no qual a matéria orgânica é digerida na presença de uma solução ácida e básica.

A fração glicídica das amostras foi calculada pela diferença, considerando a matéria integral, segundo a equação: 


$$
\begin{aligned}
\% F G=100- & {[\% \text { umidade }+\% \text { extrato etéreo }} \\
& +\% \text { proteína bruta }+\% \text { fibra bruta } \\
& +\% \text { cinzas }]
\end{aligned}
$$

O cálculo da energia foi realizado com base no teor de proteínas, carboidratos e lipídios das amostras, de acordo com Mahan \& Escott-Stump (2002), usando-se a equação: E (kcal) = (proteínax4,0) + (carboidratox4,0) + (lipídiox9,0).

Para a determinação da coloração foi utilizado o colorímetro digital Minolta CR4000, fonte de luz D65 em espaço de cor L*a*b* do sistema CIE L*a*b, a $25^{\circ} \mathrm{C}$. A calibração foi realizada com placa branca padrão, seguindo as instruções do fabricante. Os resultados foram expressos em $\mathrm{L}^{*}$ (luminosidade) que varia de 0 (preto) a 100 (branco) (Macguire, 1992).

O tempo mínimo de cocção (TMC) do arroz foi determinado utilizando $4 \mathrm{~g} / 135 \mathrm{~mL}$ de água destilada em béquer com uma placa aquecedora a $110^{\circ} \mathrm{C}$ e banho-maria a $95^{\circ} \mathrm{C}$. Após dez minutos em ebulição constante foram retirados aproximadamente dez grãos de arroz, espalhando-os sobre uma placa de vidro e pressionando-os firmemente com placas menores. A amostragem foi repetida a cada minuto até que os grãos estivessem totalmente transparentes (Bassinello et al., 2004).

Para a análise de absorção de água do arroz foi pesado $2 \mathrm{~g}$ em $40 \mathrm{~mL}$ de água destilada em tubo de ensaio vedado, utilizando-se banho-maria a $95^{\circ} \mathrm{C}$. O processo foi interrompido no tempo mínimo de cocção previamente estabelecido (Bassinello et al., 2004).

O delineamento experimental adotado foi em blocos ao acaso, em que cada bloco representou uma repetição, em esquema fatorial $2 \times 3$ com três repetições. O primeiro fator referiu-se às cultivares e o segundo às doses de nitrogênio de $0 ; 80$ e $240 \mathrm{~kg}$ $\mathrm{ha}^{-1} \mathrm{de} \mathrm{N}$.

Os dados foram submetidos à análise de variância (ANOVA) utilizando o teste $F(p \leq 0,05)$ e a comparação de médias feita pelo teste de Tukey a 5\% utilizando o programa SISVAR (Ferreira, 2000).

\section{RESULTADOS E DISCUSSÃO}

Os teores de umidade, lipídeos, cinzas e carboidratos, bem com o tempo de cocção, foram influenciados significativamente pela interação dos fatores doses de nitrogênio e tipos de cultivares (Tabela 1). O teor de umidade foi significativamente superior na cultivar BRS Primavera quando esta recebeu aplicação de 80 e $240 \mathrm{~kg} \mathrm{ha}^{-1}$ de N. Porém, todos os valores encontrados estão dentro dos limites de até $14 \%$ estabelecidos pela Instrução Normativa 06/2009 e 02/2012 do Ministério da Agricultura, Pecuária e Abastecimento (MAPA) (Brasil, 2009). A determinação do teor de umidade é um importante aspecto a respeito da conservação e da qualidade desse cereal, o qual pode ser influenciado principalmente pelo processo de secagem, acondicionamento e armazenamento dos grãos (Bortolini, 2010).

Polesi et al. (2014) ao realizarem a caracterização físico-química, funcional e nutricional de duas cultivares brasileiras de arroz, obtiveram teores de umidade de $9,7 \%$ e $10,0 \%$ para as cultivares IAC 202 e IRGA 417 respectivamente, valores dentro dos limites estabelecidos pela normativa vigente. Por sua vez, Bortolini (2010) também encontrou valores próximos ao analisar a composição centesimal do arroz parboilizado $(10,3 \%)$ e do seu subproduto $(10,81 \%)$.

A cultivar BRS Sertaneja apresentou valores significativamente inferiores de lipídios e cinzas com a aplicação de doses de $240 \mathrm{~kg} \mathrm{ha}^{-1}$ de N. Polesi et al. (2014) encontraram valores de lipídeos de 0,2\% para amostras de IAC 202 e 0,3\% para IRGA 417. Já Pereira et al. (2015), ao caracterizarem a composição centesimal de três amostras de arroz comercial branco polido com diferentes teores de amilose, encontraram teor maior que o mencionado na literatura, variando entre 1,09 a 1,37\%. Os autores associaram essas variações às características genotípicas dos grãos (Pereira et al., 2015). 
Tabela 1. Valores médios das características físico-químicas das cultivares BRS Primavera e BRS Sertaneja submetidas à aplicação de doses de nitrogênio.

\begin{tabular}{|c|c|c|c|c|c|c|c|c|}
\hline \multirow{3}{*}{ Doses de Nitrogênio } & \multicolumn{8}{|c|}{ Caraterísticas físico químicas } \\
\hline & \multicolumn{8}{|c|}{ Cultivar BRS Primavera } \\
\hline & Umidade (\%) & Lipídios (\%) & Cinzas $(\%)$ & $\begin{array}{c}\text { Carboidrato } \\
(\%)\end{array}$ & Fibras (\%) & $\begin{array}{c}\text { Valor } \\
\text { Calórico }\end{array}$ & $\begin{array}{c}\text { Tempo de } \\
\text { cocção } \\
\text { (min) }\end{array}$ & $\begin{array}{c}\text { Absorção de } \\
\text { água }(\%)\end{array}$ \\
\hline 0 & $8,18 b B$ & $0,79 \mathrm{abA}$ & $0,55 \mathrm{aA}$ & $81,27 \mathrm{aA}$ & $1,13 \mathrm{aA}$ & $364,42 \mathrm{aA}$ & $27 \mathrm{aA}$ & $557 \mathrm{aA}$ \\
\hline 80 & $9,06 \mathrm{aA}$ & $0,60 \mathrm{bA}$ & $0,49 \mathrm{aA}$ & $80,36 \mathrm{aA}$ & $1,11 \mathrm{aA}$ & $360,36 \mathrm{aA}$ & $23 \mathrm{bB}$ & $459 \mathrm{aA}$ \\
\hline \multirow[t]{2}{*}{240} & $9,33 \mathrm{aA}$ & $0,94 \mathrm{aA}$ & $0,58 \mathrm{aA}$ & $79,86 \mathrm{aA}$ & $1,11 \mathrm{aA}$ & $360,61 \mathrm{aA}$ & $28 \mathrm{aA}$ & $483 \mathrm{aA}$ \\
\hline & \multicolumn{8}{|c|}{ Cultivar BRS Sertaneja } \\
\hline 0 & $8,79 \mathrm{aA}$ & $0,65 \mathrm{aA}$ & $0,41 \mathrm{aA}$ & $78,31 \mathrm{bB}$ & $1,11 \mathrm{aA}$ & $361,97 \mathrm{aA}$ & $27 \mathrm{aA}$ & $515 \mathrm{aA}$ \\
\hline 80 & $8,22 \mathrm{aB}$ & $0,61 \mathrm{aA}$ & $0,55 \mathrm{aA}$ & 79,99abA & $1,10 \mathrm{aA}$ & $363,55 \mathrm{aA}$ & $29 \mathrm{aA}$ & $504 \mathrm{aA}$ \\
\hline 240 & $8,8 \mathrm{aB}$ & $0,37 \mathrm{aB}$ & $0,37 \mathrm{aB}$ & $81,25 \mathrm{aA}$ & $1,11 \mathrm{aA}$ & $360,72 \mathrm{aA}$ & $28 \mathrm{aA}$ & $517 \mathrm{aA}$ \\
\hline
\end{tabular}

*Médias seguidas pela mesma letra minúsculas na coluna não diferem estatisticamente pelo teste Tukey a 5\% de probabilidade entre as doses dentro da mesma cultivar

* Médias seguidas pela mesma letra maiúscula na coluna não diferem estatisticamente pelo teste Tukey a 5\% de probabilidade entre as doses nas diferentes cultivares 
As cinzas correspondem aos resíduos inorgânicos oriundos da queima da matéria orgânica e são constituídas de minerais, sendo que no arroz polido e integral são encontrados, principalmente, fósforo, potássio e magnésio (Juliano \& Bechtel, 1985). Silva et al. (2007), ao analisarem a composição química média de farinha de quirera de arroz, encontraram teores de cinzas em torno de $0,47 \%$, valores próximos ao do presente estudo. Esses nutrientes podem ser perdidos com o polimento do grão (Walter et al., 2008).

Observou-se que o teor de carboidratos foi significativamente inferior na cultivar BRS Sertaneja na ausência da adubação nitrogenada. Pagnan et al. (2015) ao caracterizarem química, física e sensorialmente três genótipos de arroz polido de cultivo irrigado, encontraram valores de carboidratos totais de $89,41 \%$ para a cultivar IRGA 417 e 89,87\% para a cultivar Moti. Enquanto Walter et al. (2008) ao examinarem a composição do arroz, suas características nutricionais e o melhoramento destas características através da genética, encontraram resultados de $87,58 \%$ de carboidratos totais no arroz branco polido. Os autores atribuíram estas variações ao genótipo e processamento do grão refletindo significativamente no percentual de amido que, por sua vez, pode interferir na textura do grão após o cozimento (Walter et al., 2008).

Os teores de proteínas foram influenciados significativamente apenas pelas cultivares (Tabela 2). Segundo Souza et al. (1998), a adubação nitrogenada promove incremento proteico do grão, aumentando seu valor nutricional, o que não foi verificado neste trabalho. Ainda segundo estes autores, isso pode variar com a época e forma de aplicação e com a cultivar. A BRS Sertaneja apresentou valores significativamente superiores aos encontrados para a cultivar BRS Primavera.

Tabela 2. Valores médios das características físico-químicas de cultivares de arroz.

\begin{tabular}{lcc}
\hline \multicolumn{1}{c}{ Componentes } & \multicolumn{2}{c}{ Cultivares } \\
\cline { 2 - 3 } & BRS Sertaneja & BRS Primavera \\
\hline Proteina (\%) & $9,36 \mathrm{a}$ & $8,08 \mathrm{~b}$ \\
Rendimento de grãos inteiros (\%) & $50,34 \mathrm{~b}$ & $83,48 \mathrm{a}$ \\
Variável L* & $53,07 \mathrm{~b}$ & $59,52 \mathrm{a}$ \\
\hline *Médias seguidas pela mesma letra minúsculas na linha não diferem estatisticamente pelo teste Tukey a 5\% de probabilidade entre \\
as cultivares
\end{tabular}

Ao avaliarem treze espécies de arroz integral cru, Mingotte et al. (2012) não observaram o incremento no conteúdo proteico dos grãos da cultivar BRS Primavera com o uso crescente de nitrogênio em cobertura, corroborando com os dados do presente estudo.

Segundo Kennedy \& Burlingame, (2003) os teores de proteína variam entre 5 e $13 \%$, os valores de 8,08 e $9,36 \%$ estão dentro da faixa mencionada e superiores a $7 \%$, que segundo esses autores é um valor considerado baixo.

Os teores de fibra bruta não foram influenciados significativamente pela interação doses e cultivares e nem pelas variáveis isoladas. A cultivar
BRS Sertaneja apresentou uma média de fibra bruta de $1,10 \mathrm{~g} 100 \mathrm{~g}^{-1}$, enquanto a cultivar BRS Primavera

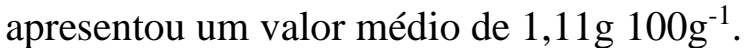

As fibras dietéticas alimentares são substâncias componentes dos tecidos vegetais que não constituem fonte de energia por não serem hidrolisadas pelo organismo humano (Silva et al. 2007). Valores superiores de fibras foram encontrados por Polesi et al. (2014) nas espécies de arroz IAC 202 e IRGA 417; no entanto, é válido ressaltar que os autores fizeram a determinação de fibra alimentar e já no presente estudo determinou-se o teor de fibra bruta que subestima os valores de fibra em função da determinação apenas da porção 
insolúvel em ácido. Walter et al. (2008) associaram o polimento do grão a perdas significativas de muitos nutrientes, dentre esses as fibras alimentares.

O valor calórico não foi influenciado significativamente pelas doses de nitrogênio ou cultivares. Entretanto, os valores encontrados no presente estudo foram superiores aos registrados na Tabela de Composição de Alimentos - TACO (2011) que tem como valor calórico do arroz cru em 100 gramas o equivalente a $358 \mathrm{Kcal}$. Já a Tabela de Composição Química de Alimentos da Universidade de São Paulo (2016) traz um valor de $340 \mathrm{kcal}$.

Pereira et al. (2015) encontraram valores que variaram de 355,91 a $363,30 \mathrm{kcal}$ ao caracterizarem a composição centesimal de três amostras de arroz comerciais com diferentes teores de amilose.

Quanto ao tempo médio de cocção, o mesmo foi influenciado significativamente pela interação doses de nitrogênio e cultivares (Tabela 1). O tempo de cocção foi inferior para a cultivar BRS Primavera adubada com $80 \mathrm{~kg} \mathrm{ha}^{-1}$ de $\mathrm{N}$.

Ao realizarem a caracterização físicoquímica, funcional e nutricional de duas cultivares brasileiras de arroz, Polesi et al. (2014) encontraram um tempo mínimo de cocção de 17,7 minutos para a cultivar IAC 202 e 17 minutos para a cultivar IRGA 417. No entanto, Silva et al. (2006) ao avaliarem o efeito da adubação com nitrogênio e molibdênio em grãos de feijão, constataram que o tempo de cozimento foi maior à medida que houve incremento de nitrogênio aplicado em cobertura. Os autores correlacionaram o acréscimo no tempo de cocção ao aumento do teor proteico dos grãos, devido às características hidrofílicas da molécula de proteína necessitando assim de maior tempo para desnaturação proteica (Silva et al., 2006).

O percentual de absorção de água não foi influenciado pelas doses de nitrogênio ou cultivares. Polesi et al. (2014) encontraram maior absorção de água na cultivar IAC $202(459,7)$ quando comparado com a cultivar IRGA 417 (495,3), sendo estes valores inferiores aos encontrados no presente estudo. Esse comportamento pode estar relacionado à diferença nos teores de amilopectina das cultivares, visto que esta fração do amido é a principal responsável pela expansão dos grânulos de amido durante a gelatinização (Songe \& Jane, 2000).

O percentual de rendimento de grãos inteiros após o beneficiamento foi influenciado apenas pelas cultivares (Tabela 2). A cultivar BRS Primavera apresentou percentuais médios significativamente superiores aos apresentados pela cultivar BRS Sertaneja.

Um critério importante tanto para a comercialização, quanto para definir a qualidade do arroz é o percentual de grãos beneficiados. Não é atrativo para o consumidor um produto com maior quantidade de grãos quebrados, pois este resulta em um cozimento desuniforme (Mingotte et al., 2012). É considerado fora das exigências para comercialização valores abaixo de $40 \%$ de grãos inteiros e $28 \%$ de grãos quebrados e quirera (Fornasieri Filho \& Fornasieri, 2006).

Ao analisar a resposta de cultivares de arroz irrigado com adubação nitrogenada, Freitas et al. (2001) encontraram para a cultivar IAC 101 um efeito positivo com a aplicação de nitrogênio no rendimento dos grãos inteiros aumentando de 34 para 42\%, com um incremento das doses de nitrogênio de 0 para 150 $\mathrm{kg} \mathrm{ha}^{-1}$ de N. Já para as cultivares IAC 102 e IAC 104 os autores não observaram o efeito da adubação nitrogenada sobre o rendimento de grãos inteiros, que foram, em média, de 39 e 55\%, respectivamente.

Mingotte et al. (2012) concluíram que a variável rendimento de grãos inteiros é mais influenciada pelo genótipo da cultivar e por fatores ambientais no momento da colheita do que pela aplicação de nitrogênio.

Os valores da variável $\mathrm{L}$ foram influenciados significativamente apenas pelas cultivares (Tabela 2). De acordo com os resultados a cultivar BRS Sertaneja apresentou valores significativamente inferiores $(53,07)$ aos encontrados para a cultivar BRS Primavera $(59,52)$.

A variável L é conhecida como luminosidade e se estende de 0 que é mais próximo da cor preta a 100 mais próximo do branco (Polesi et al., 2014). Segundo Zanão et al. (2009), a cor é um importante 
aspecto para a determinação da qualidade do arroz, visto que ao avaliarem a aceitabilidade para cor do arroz observaram que a preferência do consumidor é pelo arroz mais branco.

Polesi et al. (2014) encontraram valores de L para a cultivar IAC 202 de 73,5 e 68,4 para a cultivar IRGA 417, indicando cultivares de arroz com uma coloração mais branca quando comparadas às cultivares do presente estudo.

\section{CONCLUSÕES}

A adubação nitrogenada não interfere no percentual de proteína e no percentual de rendimento de grãos inteiros. A cultivar BRS Primavera apresenta maior percentual de rendimento de grãos inteiros, enquanto que a cultivar BRS Sertaneja apresenta maiores teores de proteína e grãos de coloração mais escura.

\section{REFERÊNCIAS BIBLIOGRÁFICAS}

AOAC - Association of Official Analytical Chemists. (2000). Official methods of analysis of the Association Analytical Chemits. $17^{\mathrm{a}}$ ed Arlington: AOAC Inc., v.1 e v. 2.

Bortolini, V.M.S. (2010). Determinação da composição centesimal do arroz parboilizado (oriza sativa) e seu subproduto. Revista Congrega URCAMP, 8:1-7.

Bassinello, P.Z.; Rocha, M.S \&Cobucci, R.M.A. (2004). Avaliação de diferentes métodos de cocção de arroz de terras altas para teste sensorial. Comunicado Técnico da Embrapa Arroz e Feijão, n. 84.

BRASIL. (2014). Ministério da Saúde. Guia alimentar para a população brasileira: promovendo a alimentação saudável. Brasília (Série A. Normas e Manuais Técnicos).
BRASIL. (2009). Instrução Normativa no 6, de 19 de fevereiro de 2009. Regulamento Técnico do Arroz. Diário Oficial da União, Brasília.

Breseghello, F.; Morais, O.P.; Castro, E.M.; Pereira, J.Á.; Utumi, M.M.; Lopes, A.M.; Cordeiro, A.C.C.; Bassinello, P.; Fonseca, J.R.; Prabhu, A.S.; Peters, V \& Soraes, A.A. (2006). BRS Sertaneja: cultivar precoce de arroz de terras altas. Santo Antônio de Goiás, Embrapa Arroz e Feijão. 4p. (Comunicado Técnico, 133).

Buzetti, S.; Bazanini, G.C.; Freitas, J.G.; Andreotti, M.; Arf, O.; Sa, M.E. \& Meira, F.A. (2006). Resposta de cultivares de arroz a doses de nitrogênio e do regulador de crescimento cloreto de clormequat. Pesquisa Agropecuária Brasileira, 41 (12):17311737.

CONAB - Companhia Nacional de Abastecimento. (2019). Acompanhamento da Safra Brasileira de Grãos - Safra 2018-2019. $8^{\circ}$ Levantamento. 69p.

Cuevas-Perez, F. \& Peske, S.T. (1990). Milimg performance of rice varieties under different moisture absorption environments. Tropical Science, London, 30: 142-152.

Fageria, N.K.; Santos, A.B. \& Cutrim, V.A. (2007). Produtividade de arroz irrigado e eficiência de uso do nitrogênio influenciadas pela fertilização nitrogenada. Pesquisa Agropecuária Brasileira, 42(7):1029- 1034.

Ferreira, D.F. (2000). Análises estatísticas por meio do SISVAR (Sistema para análise de variância) para Windows versão 4.0. In: Reunião Anual da Região Brasileira da Sociedade Internacional De Biometria, 45. 2000, São Carlos. Anais... São Carlos: UFSCar. p. 255-258.

Fornasieri Filho, D. \& Fornasieri, J. L. (2006). Manual da cultura do arroz. Jaboticabal: FUNEP.589 p. 
Freitas, J.G.; Azzini, L.E.; Cantarella, H.; Bastos, C.R.; Castro, L.H.S.M.; Gallo, P.B. \& Felício, J.C. (2001). Resposta de cultivares de arroz irrigado ao nitrogênio. Scientia Agrícola, Piracicaba, 58 (3):573-579.

Juliano, B.O. \& Bechtel, D.B. (1985). The rice grain and its gross composition. In: JULIANO, B.O. (Ed.). Rice: chemistryand technology. Minnesota, USA: American Association of Cereal Chemistsp.17-57.

Kamer, J.H.V. \& Ginkel, L. (1952). Rapid determination of crude fiber in cereais. Cereal Chemistry, Saint Paul, 29(4):239-251.

Kennedy, G. \& Burlingame, B. (2003). Analysis of food composition data on rice from a plant genetic resources perspective. Food Chemistry, 80(4):589596.

Lanna, A. C.; Ferreira, C. M. \& Barrigossi, J. A. F. (2003). Impacto ambiental e econômico da cultura de arroz de terras altas: caso da cultivar BRS Primavera. Santo Antônio de Goiás: Embrapa Arroz e Feijão, 4 p. (Embrapa Arroz e Feijão. Comunicado técnico, 58).

Macguire, R.G. (1992). Reporting of obective color measurements.

HortScience, Alexandria, 27(12):1254-1555.

Mahan, L.K. \& Escott-Stump, S. (2002). Alimentos, nutrição \& dietoterapia. $10^{\mathrm{a}}$. ed. São Paulo: Roca. p. 1157.

Mingotte, F.L.C.; Hanashiro, R.K. \& Filho, D.F. (2012). Características físico-químicas do grão de cultivares de arroz em função da adubação nitrogenada. Semina: Ciências Agrárias, Londrina, 33 (1):2605-2618.

Naves, M.M.V. (2007). Características químicas e nutricionais do arroz. Boletim CEPPA, 25:51-60.
Oliveira, M; Paraginski, R. T; Ziegler, V; Talhamento, A. \& Elias, M. C. (2014). Propriedades tecnológicas e de cocção em grãos de arroz condicionados em diferentes temperaturas antes da parboilização Braz. J. Food Technol, Campinas, 17(2):146-153.

Pagnan, M.F.; Bassinello P.Z. \& Prudencio S.H. (2015). Características sensoriais, físicas e químicas e aceitação de arroz irrigado ou de terras altas. Pesquisa Agropecuária Brasileira, 50(10):979-988.

Pereira, A.M.; Avila, B.P.; Gularte, M.A.; Alves, G.D.; Monks, J.; Madruga, K. M. \& Silveira, L. (2015). Caracterização Centesimal, Tempo de Cocção e Perfil de Textura de Arroz Com Diferentes Teores de Amilose. In: Anais IX Congresso Brasileiro de Arroz Irrigado: Ciência e Tecnologia para a Otimização da Orizicultura, Pelotas.

Polesi, L.F.; Lima, D.C.; Morais, P.G.; Romo, I.C.F.; Sarmentos. B.S. \& Brazaca, S. G.C. (2014). Caracterização físico-química, funcional e nutricional de duas cultivares brasileiras de arroz. Revista Brasileira de Tecnologia Agroindustrial, 8:1262-1273.

Sgarbieri, V. C. (1986). Fontes de proteínas na alimentação. In: Proteínas em alimentos proteicos. São Paulo: Varella. p. 139-257.

Silva, R. F.; Ascheri, J. R.L. \& Pereira, R. G. F. A. (2007). Composição centesimal e perfil de aminoácidos de arroz e pó de café. Alimentos e Nutrição, Araraquara, 18(3):325-330.

Silva, T.R.B.; Lemos, L.B. \& Tavares, C.A. (2006). Produtividade e característica tecnológica de grãos em feijoeiro adubado com nitrogênio e molibdênio. Pesquisa Agropecuária Brasileira, 41(5):739-745.

Song, Y. \& Jane, J. (2000). Characterization of barley starches of waxy, normal and high amylose varieties. Carbohydrate Polymers, 41(4):365-377. 
Souza, S. R., Stark, E. M. L. M. \& Fernandes, M. S. (1998). Nitrogen remobilization during the reproductive period in two brazilian rice varieties. Journal of Plant Nutrition, 21(10):2049- 2063.

Taco. (2011). Tabela Brasileira de Composição de

Alimentos. $4^{\mathrm{a}}$ ed. revisada e ampliada. Campinas, SP: UNICAMP.

Universidade de São Paulo. (2018). Faculdade de Ciências Farmacêuticas. Tabela de composição química de alimentos. Disponível em: <http://fcf.usp.br>. Acesso em: 12 set. 2018.

Walter, M.; Marchezan, E. \& Avila, L.A. (2008). Arroz: composição e características nutricionais. Ciência Rural, 38(4):1184-1192.

Zanão, C.F.P.; Brazaca, S.G.C.; Sarmento, S.B.S. \& ARTHUR, V. (2009). Efeito da irradiação gama nas características físico-químicas e sensoriais do arroz (Oryza sativa L.) e no desenvolvimento de Sitophilus oryzae L. Ciência e Tecnologia Alimentos, Campinas, 29(1):46-55. 